\title{
Bulletin of The British Association of Sport and Medicine
}

\author{
ChALlenge! - \\ THE B.A.S.M.'s ROLE IN HEALTH EDUCATION
}

By C. C. LUTTON

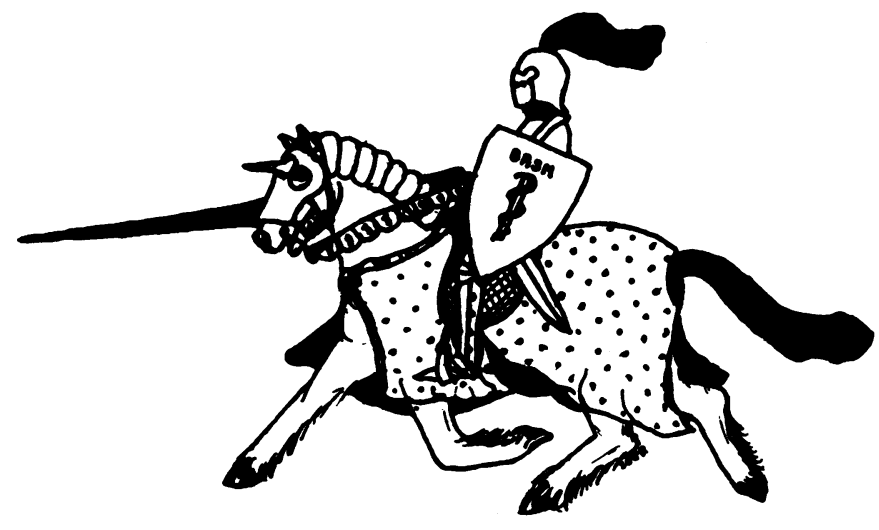

To the National Health Service and the Medical Profession

The first 30 year phase of the NHS has established the need for efficient medical services, but the cost effectiveness must now be challenged and it must be recognised that more work must be done regarding priority and phasing of services in the next 30 year phase, ie "Prevention of IIIness" and "Health Education" services, on the basis that "Disease Medical Services" could eventually cripple the economies of nations with falling birth rates and increasing numbers of ill and elderly people. The emphasis should be on not necessarily living longer but living, working and playing better.

One of the main factors in disease prevention should be based on "Sport for All" and the complexity of the various associated problems in setting up the necessary preventative medical services must now be examined by those with forethought, initiative and the practical knowledge regarding what is required.

The cost of the NHS for 1977 was $16500 \mathrm{~m}$ and this figure is bound to increase alarmingly in the next 15 years as a result of the failures of the last $\mathbf{3 0}$ years due to such factors as smoking, obesity, lack of exercise, alcohol, noise, TV, unhealthy work factors, absence of screening programmes etc.

The 1978 budget for British Health Education programme was $£ 3 \mathrm{~m}$ and overwhelming support must be given in order that this budget may become more realistic in view of what will be required, in the future. It must be recognised that there will be overlap in the various fields of medical thought and activity for the future. "Sport for All" is bound to overlap into the field of "Health for All" in the same way that the Scottish Health Education Unit's "Fit for Life" campaign must, of necessity, have a sports medicine component.

It may be that BASM wishes to remain all time "small time" and confine itself to assisting medal winners to win more medals, but it is in the interests of the nation that "Sport for All" means medical attention for all during sport and inter-related activities.

Screening of children at 5 years old, 12 years old and 16 years old, should be done in an organised way, as there is a relationship between fitness for sport, fitness for school and fitness for work in later life. It may be argued that Sports Medicine Services should have an inter-relationship with Occupational Medicine Services as well as School Medical Services.

At this time the various interested bodies should come together; the Minister for Sport, Home and Health Department, Department of Education, Health Education Unit, BMA, The Sports Council and BASM. At this stage it would be better that the ideas come from the various voluntary bodies rather than formal Government Units and a meeting should be arranged at some time in the future with a view to bringing representatives of involved spheres with sports medicine to setting up a programme in order to get the necessary end result. Various associated factors could be considered at this stage and promoted by BASM. 
(a) Promote a Professorial Chair of Sports Medicine at a Medical School. A target of $£ 3 \mathrm{~m}$ may be required, some of which might be raised from industry and some from Government sources, provided sufficient impact was made; all Members of Parliament to be contacted by their personal general practitioner and in the same way others who might be in a position to be influenced, Captains of Industry, Chairman of Health Boards, and all organisations connected with Sport.

The aim of a Professorial Unit should be a flow of trained personnel in the medical aspects of sport whether doctors, physiotherapists or coaches.

(b) The news media should be pressurised at all levels to emphasise the need for sport and sports medicine facilities and necessary training of personnel to be involved.

(c) The old Public Health Department and Schools Medical Services, which, with reorganisation of Medical Services, are now part of Community Medical Services, should be advised to consider expansion into the Sports Medical Services field. The Schools Community Health Service physicians examine childrens' eyesight and look for hip-joint disease and arrange inoculation programmes and there is a case for expansion of their role and this would involve special training for Community Physicians. The Community Physicians' Committee of the BMA should be invited to discuss the problem.

(d) Increasing contact and inter-relationship with the Health Education Unit with a view to increasing the range and activity of both bodies and particularly with a view to increasing the budgets.

(e) BASM should set up a panel of experts available to give advice at local level to organisations connected with all manner of sports, for example, the manager and the Union of a local factory who wish to set up a football team; a Rugby Club who feel that some form of first aid room be set up at their Club House.

(f) Eventual premises and staffing on a full-time basis. $1 \%$ of the budget of the NHS would not be unreasonable to ask for and this would result in the apparently staggering sum of $165 \mathrm{~m}$ per annum available to Sports Medicine in terms of 1978 NHS expenditure.

\section{CORRESPONDENCE}

From Pedro Paulo de Oliveira

Professor of Physical Education, University of Recife

To the Editor

Dear Sir,
Appt'o 301 Boa Viagem, Av. Conselheiro Aguiar 1515, RECIFE 50,000, Brazil.

January 22nd, 1979

\section{SPORTING LONGEVITY}

Nowadays exercise, and the practice of sport, are the greatest resources for prolonging the lifetime of the human being. In a modern programme of exercises, care in breathing correctly and increasing the capacity of oxygen absorption take us through a controlled effort, to the acquisition of stronger lungs and heart, lessening heart rate. The reduction of the heart rate and the hypertrophy of the myocardium, propitiate a bigger demand of blood supply to the muscles, increasing local capillarity and bringing nutrition.

With the growth of oxygen absorption, we improve the capacity of the cells to nourish themselves, mobilizing greater resources of energy, and giving better physical endurance. This brings us to believe that all these factors contribute to the lengthening of the life-span of human beings.

It is a fact that the better athletes in various sports have only a short period of participation. The records give clear proof of the preoccupation of trainers with better training techniques, in search of better athletic performance, without the slightest worry about the biological condition of their athletes. 